Western University

Scholarship@Western

FIMS Publications

Information \& Media Studies (FIMS) Faculty

2000

\title{
Electronic Miscommunication and the Defamatory Sense
}

Jacquelyn Burkell

The University of Western Ontario, jburkell@uwo.ca

Follow this and additional works at: https://ir.lib.uwo.ca/fimspub

Part of the Library and Information Science Commons

Citation of this paper:

Burkell, Jacquelyn, "Electronic Miscommunication and the Defamatory Sense" (2000). FIMS Publications. 69.

https://ir.lib.uwo.ca/fimspub/69 


\title{
ELECTRONIC MISCOMMUNICATION AND THE DEFAMATORY SENSE
}

\author{
Jacquelyn Burkell and Ian R. Kerr*
}

\section{I.Introduction}

Imagine being invited to attend and present at an international conference. Imagine sitting in the lecture hall, ready to deliver your research results to colleagues and friends, most of whom - like you yourself - are internationally renowned and respected. You await your introduction to the audience. The host of the conference takes the podium. But, instead of hearing her recite highlights from your long list of accolades, you are introduced to the audience in the following manner:

I have met [John Doe] myself, and my impression is that his entire career has been built not on ... research at all, but on an ability to berate and bully all and sundry ... In the local pub, drinking and chain smoking all the while for that matter.

Secondly, and this is rumours passed to me by several reputable and long-standing German academics as to his "Puppy Parties" focused I am told on a local boy they called "Puppy". Hmm, strange dicey behaviour indeed, especially here in an environment dominated by conservative fundamentalists.

Believe it or not, these words were actually spoken at a relatively recent academic conference. ${ }^{1}$ The speech was not idle chatter amongst private interlocutors, gossiping in the back row of a crowded auditorium in between presentations. Rather, the words were announced from the podium. These shocking accusations about an internationally reputed scholar - the head of his Anthropology

\footnotetext{
* Dr. Jacquelyn Burkell, Faculty of Information and Media Studies, The University of Western Ontario and Dr. Ian R. Kerr, Faculty of Law, Common Law Section, The University of Ottawa. The authors would like to thank Gila Bell, Carole Johnson, and Bernard Sandler for their extraordinary research assistance.

${ }^{1}$ See Rindos v. Hardwick, [1994] ACL Rep. 145 WA 4 (Sup. Ct.).
} 
Department and the author of numerous publications of sufficient import to warrant their translation into several languages - were made at an international conference of anthropologists, a conference of several thousand academics representing almost every major university in the world. As it turns out, none of the accusations were true.

It is certainly difficult to envision such awful things being said publicly at any civilized symposium. One is therefore tempted to ask: what circumstances could possibly have led to this event? Where was the conference moderator during all of this? And, where in the world would an academic dialogue allow for such an uncultured, unkind and insidious rebuke? The answer is that it happened in cyberspace. That is, the malicious statements were communicated in the context of an online computer conference.

One potential reaction to this last bit of information, namely, that it happened on the Internet, is to minimize the significance of the event. After all, every academic who has visited a Usenet discussion group or a real-time chat room on the World Wide Web knows that these places represent the best argument there ever was in favor of cultural nihilism. Many academics think of the Internet as a vast electronic wasteland where everyone is allowed to say whatever they want to whomever will listen. Even if you feel this way about the Internet, even if you are not an enthusiast about the Internet's potential as a communications medium, it is important to remember that online events are sometimes of tremendous significance to real life events.

To continue our example, the cruel and false statements cited above were made about a real life person - a university professor in Australia named David Rindos. As fate would have it, the horrible lies told about David Rindos were communicated to the world's largest network of anthropologists just a few days after the formal announcement of a decision by the University of Western Australia not to grant him tenure. Imagine the emotional turmoil David Rindos was forced to endure learning that, in addition to losing his academic position, he would also lose the excellent reputation that he had spent his entire career building - all within the span of just one week. It would 
be extremely difficult for David Rindos to get another academic position after failing to get tenure. But it would be practically impossible for him to obtain any such position after being branded an incompetent scholar and a pedophile. Especially if other universities were under the mistaken impression that the online accusations against David Rindos had some bearing on his dismissal from the University of Western Australia. Here, one is reminded of the famous words spoken by Shakespeare's Iago to Othello:

Good name in man and woman, dear my lord,

Is the immediate jewel of their souls:

Who steals my purse steals trash; 't is something, nothing;

'T was mine, 't is his, and has been slave to thousands;

But he that filches from me my good name

Robs me of that which not enriches him

And makes me poor indeed. ${ }^{2}$

With the advent of digital media, which facilitate the physical and temporal separation of speaker and audience, the stripping away of the non-linguistic aspects of communication, and the increased sense of anonymity of interlocutors who are neither seen nor heard by one another, one wonders whether the immediate jewel of our souls is more easily filched now than it was in the predigital age. The aim of this article is to commence an investigation of what defamation means in the online setting. Although online defamation is a global phenomenon and therefore a global issue, the current investigation will be restricted to a study of the common law approach to online defamation. ${ }^{3}$ Our goal is to determine whether there are any unique aspects of electronic communication and, if so,

${ }^{2}$ W. Shakespeare, Othello, The Moor of Venice, Act III scene iii.

3 There is perhaps a larger and perhaps more important question - namely, whether a uniform approach to defamation might be formulated at the global level. Although a comprehensive response to the larger question is beyond the scope of the present inquiry, this investigation of the common law approach serves as a useful point of departure. 
whether the uniqueness of electronic communication necessitates additional common law considerations when determining whether a particular communication carries a defamatory sense.

It should be admitted at the outset that the popular view espoused by traditional common law scholars is that society's recent infatuation with the Internet is purely hype and that those who purport to investigate 'Internet Law' do so at risk of "multi-disciplinary dilettantism." Academics who subscribe to this point of view tend to deny that the Internet raises any novel legal questions. For example, in the Introduction to his book on Media Law, Professor Martin has stated that

There is no reason of principle or of logic to treat online computer services differently from any other medium of communication. I can only assume, for example, that a libel published through the Internet would be dealt with in exactly the same way that a libel published in a newspaper is dealt with. ${ }^{5}$

The fundamental premise underlying Professor Martin's outlook is that the medium of communication is irrelevant to any inquiry as to the content of its message.

This, of course, is tantamount to the assertion that the "message is the message" - which appears to be in direct contradiction to McLuhan's famous aphorism, "the medium is the message". 6 McLuhan's assertion implies that the meaning or influence of any medium is independent of the content it carries. It should be noted, however, that for McLuhan the 'message' of a medium is 'the sum of the changes that result from social use - the transformations in society that have come about through the use of an object ('medium')'7 Thus, for McLuhan, the use of a medium changes the world around us, and the content carried in that medium is interpreted in the context of this changed world. ${ }^{8}$

\footnotetext{
${ }^{4}$ See e.g. F.H. Easterbrook, "Cyberspace and the Law of the Horse" (1996) U. Chi. Legal F. 207.

${ }^{5}$ R. Martin, Media Law (Concord, ON: Irwin Law, 1997) at 2.

${ }^{6}$ M. McLuhan, Understanding Media (New York: McGraw Hill, 1964) at 9.

${ }^{7}$ S.D. Neill, Clarifying McLuhan: An Assessment of Process and Product (Westport, Connecticut: Greenwood Press, 1993) at 58.

${ }^{8}$ M. McLuhan, Understanding Media (New York: McGraw Hill, 1964) at 7.
} 
This interpretation is entirely consistent with the central theme of this paper: the use of electronic media for communication alters the social context within which these communications are both produced and received, and thus the content of communication can be understood only when this modified context is taken into account.

In this article, we argue that the content of communication - specifically, content that might be interpreted as defamatory - must be examined in light of the context in which it is delivered. First, we will attempt to provide a partial explanation for the recent proliferation of defamation lawsuits resulting from electronic communication. ${ }^{9}$ To this end we begin with an account of what it is that makes a statement defamatory, from a legal point of view. We then examine the effect that digital technology has had on the culture of communication. In particular, we argue that the lack of certain extra-linguistic cues and the absence of established cultural norms in the electronic environment often

9 Recent online defamation cases in Canada include: Braintech v. Kostiuk, (1999) 171 D.L.R. (4th) 46; Investors Group Inc. v. Hudson, [1998] Q.J. No. 4543, online: QL (CJ); Reform Party of Canada v. Western Union Insurance Co., (1999) 3 C.R.R. (4th) 289; Direct Energy

Marketing Ltd. v. Hillson, (1999) 72 Alta L.R. (3d) 140; Gouveia v. Toronto Star Newspapers Ltd., (1998) O.T.C. 186; Southam Inc. v. Chelekis, [2000] B.C.J. No 314, online: QL (CJ); See also, K.K. Campbell, “ISP's Buckling Under” The Toronto Star (27 April 2000); Phinjo Gombu, "Chat Room Lawsuit Challenges Net Rules" The Toronto Star (25 March 2000); Chad Skelton and David Hogben, "E-Mail Suit Covers New Ground" The Edmonton Sun (20 October 1999) 59; Staff Reporter, "Hydro Deal Released a Settlement $21 / 2$ Years in the Making" The London Free Press (4 August 1999) A9. There are also a number of recently reported cases in the U.K., see e.g., Godfrey v. Demon Internet Ltd., [1999] All E.R. 342; Irving v. Penguin Books Ltd. et al., [2000] E.W.J. No. 1897, online: QL (UKJ); Berezovsky v. Michaels,[2000] H.L.J. No. 24, online: QL (UKJ); See also Danny O’Brien, “The Net Closes In” Times Newspaper Limited (7 May 2000) Features; Frances Gibb, "Russian Free to Sue in Britain" Times Newspapers Limited (12 May 2000) Home news; Tomas Mac Ruairi, "Jailed For Gay Lies on the Net: First Case in Ireland of Cyber Libel Against Teacher 'School Nerd's' Web of Deceit” The Mirror (21 December 1999) A1. For American cases see, e.g., Cubby, Inc. v. Compuserve Inc., 776 F Supp. 135 (S.D.N.Y. 1991); Stratton Oakmont, Inc. v. Prodigy Services Co., [1995] WL 323710, 63 U.S.L.W. 2765, 23 Media L. Rep. 1794 (N.Y. Sup. Ct.), online: WL (ALLCASES); It's In the Cards, Inc. v. Fuschetto, 193 Wis.2d 429 (Wis. C.A. 1995); Zeran v. America Online, Inc., 958 F.Supp. 1124 (Va. Dist. Ct. 1997); Lunny v. Prodigy Services Co., 250 A.D. 2d. 230, 683 N.Y.S.2d 557 (Sup. Ct. App. Div. 1998); Doe v. America Online, Inc., 729 So.2d 390 (Fla. Sup. Ct. 1999); Blumenthal v. Drudge, 992 F.Supp. 44 (D.C. Dist. Ct. 1998); Mallinckrodt Medical, Inc. v. Sonus Pharmaceuticals, Inc., 989 F.Supp. 265 (D.C. Dist. Ct. 1998). 
result in miscommunication which - if not itself defamatory - gives rise to emotional exchanges between interlocutors in a manner that provokes hostile and injurious interaction. Finally, once the nature and causes of electronic miscommunication are better understood, we return briefly to the law of defamation to investigate the special considerations that the courts ought to undertake when determining whether particular statements made in the online setting should be understood in a defamatory sense.

\section{Flaming and the Need to Protect Reputations Online}

For those relatively unfamiliar with the Internet, be forewarned: online communication very often evokes personal insults and sometimes even violent expressions of disapproval. This phenomenon has its own name in cyberspace - "flaming":

\section{Flame}

1. vi. To post an email message intended to insult and provoke. 2. vi. To speak incessantly and/or rabidly on some relatively uninteresting subject or with a patently ridiculous attitude. 3 . vt. Either of senses 1 or 2 , directed with hostility at a particular person or people. 4. n. An instance of flaming. ${ }^{10}$

It is worth mentioning that most seasoned Internet users do not consider all flaming to be defamatory in nature. As one author describes it, on the Internet, "flaming foes with nasty notes has turned hyperbole into a high art."11 For this reason, says another author, "[a]nyone who plans to spend time on-line has to grow a few psychic calluses."12

${ }^{10}$ From the New Hacker's Dictionary, online: Elsewhere <http://www.elsewhere.org/jargon/jargon_21.html\#SEC28 > (date accessed: 14 June 2000).

11 J. Knight, "Free Speech Collides with Cyberspace" Washington Post (21 November 1994) 19.

12 Anonymous e-mail quoted in M. Dery, "Flame Wars" (1993) 92 South Atlantic Q. 559 
Though the need to develop a tough outer skin is seen by many Internet enthusiasts as a small price to pay for the unprecedented freedom of speech that Internet users enjoy online, it is important to remember, as David Rindos certainly will remember, that flame wars often result in personal abuse and sometimes even irreparable harm to one's reputation. This is especially so when one considers the attitudes typically adopted by Internet flamers, who offer advice such as: "make up things about your opponent" and "when in doubt, insult."13 To the extent that flaming and other phenomena associated with online interaction threaten to injure reputation, we ought to be concerned about electronic miscommunication. As Justice Stewart once stated in a famous American case prior to the popularization of electronic communication:

The right of man to the protection of his own reputation from unjustified invasion and wrongful hurt reflects no more than our basic concept of the essential dignity and worth of every human being - a concept at the root of any decent system of ordered liberty... ${ }^{14}$

To better understand how we ought to protect reputation from unjustified invasion and wrongful hurt resulting from electronic miscommunication, it is necessary to consider first how reputation has traditionally been protected in other media of communication. The formal social mechanism utilized to this end in Anglo-Canadian common law is the tort of defamation.

at 560.

${ }^{13}$ See e.g. Joe Talmadge, “The Flamer's Bible”, online: Rec.Humor.Funny Homepage <http://www.netfunny.com/rhf/jokes/88q1/13785.8.html> (last modified: 16 August 1999).

14 Rosenblatt v. Baer, 383 U.S. 75 (1966) at 92. 


\section{The Law of Defamation}

In Anglo-Canadian law, the tort of defamation is part of the private law. Although defamation might accurately be said to "embod[y] the public policy that individuals are entitled to the enjoyment of good reputations unimpaired by false ... statements", ${ }^{15}$ it is up to private individuals to commence actions against those who they claim have injured their reputations. Like any other private law dispute, the state generally has no interest in the outcome. In order to succeed in an action for defamation, the plaintiff, i.e., the person bringing the suit, must prove three things: (i) that a defamatory statement was made by the defendant; (ii) that the defamatory statement identifies and refers to the plaintiff; and (iii) that the defendant intentionally or negligently published the defamatory statement to some third party. Although, legally speaking, these are the formal elements of proof,

The essence of defamation is that the defendant has said or done something which attacks the ... reputation of the plaintiff in such a way as would tend to lead reasonable people to think less of the plaintiff, to reduce his standing in society at large. Such an attack may be through the medium of the written or spoken word. Or it might be by means of acts, which convey a defamatory meaning. ${ }^{16}$

Thus, the threshold inquiry in every defamation lawsuit is whether the words or actions of the defendant have the tendency to harm the reputation of the plaintiff. As an American scholar recently put it, this "requires the judge to undertake both a linguistic inquiry to discover the 'tendencies' of words and a sociological inquiry to discover the attitudes and beliefs of the community, for what is defamatory is a function of defamation law's unique conception of reputational harm."17

15 R.E. Brown, The Law of Defamation in Canada, vol. 2 (Toronto: Carswell, 1994) at 1.

${ }^{16}$ G.H.L. Fridman, The Law of Torts in Canada, vol. 2 (Toronto: Carswell, 1990) at 141.

${ }^{17}$ L.B. Lidsky, "Defamation, Reputation, and the Myth of Community" (1996) 71 Wash L. Rev. 1 at 11. 
What is perhaps unique about defamation law's conception of reputational harm is that it is a "recipient-centered concept"18; whether a communication is defamatory depends solely on the manner in which it would be received by a reasonable audience. Although it may at first seem remarkable, defamation is a "strict liability" offence. In other words, it matters not, in the eyes of the law, what the defamer meant, thought, or believed when the injurious remark was published. Once it is proved that a defamatory remark identifying the plaintiff has been published to some third person, the defendant in a defamation suit is held strictly liable regardless of the intent, motive, belief or degree of care exhibited in making the remark. ${ }^{19}$ As one judge put it some time ago, the test is not "whether the writer intended to speak disparagingly of [the plaintiff]... but whether what was written would, in the circumstances in which it was published, be understood in a disparaging sense by reasonable men reading it." 20

Likewise, and perhaps equally remarkable, the perceptions of the person about whom the remark was made, i.e., what he or she thought or felt as a consequence of the remark, is also deemed to be irrelevant. In the law of defamation, what matters only is that which would tend to excite a reasonable community of bystanders. To employ two of the more typical legal sound bytes, whether a communication is defamatory will depend on whether the words or acts in question expose a person to "hatred, ridicule or contempt" 21 or has the tendency to cause that person to be "shunned or avoided" by the community. ${ }^{22}$

18 M.A. Franklin and D.J. Bussel, "The Plaintiff's Burden in Defamation: Awareness and Falsity" (1984) 25 Wm. \& Mary L. Rev. 825 at 828.

${ }^{19}$ See e.g. Hulton \& Co. v. Jones, [1909] 2 K.B. 44 aff' d, [1910] A.C. 20 (H.L.); Mack v. North Hill News Ltd. (1964), 46 W.W.R. 254 (Alta. S.C.); Jones v. Bennett (1968), 63 W.W.R. 1 (B.C.C.A).

${ }^{20}$ Per Street A.C.J. in Rofe v. Smith's Newspapers Ltd. (1924), 25 S.R. (N.S.W.) 4 at 17.

${ }^{21}$ MacDonald v. Mail Printing Co. (1901), 2 O.L.R. 278 at 282-83 (C.A.).

22 Parmiter v. Coupland (1840), 6 M. \& W. 105 at 108; Youssoupoff v. Metro-Goldwyn- 
Consider the following rather stark example. About fifteen years ago, an American comedian named Robin Williams performed an ad hoc comedy routine, which was distributed in various media by Polygram Records. The routine, which was alleged to be defamatory, went as follows:

Whoa - White Wine. This is a little wine here. If it's not wine it is through somebody already. Oh. - There are white wines, there are red wines, but why are there no black wines like: REGGAE, A MOTHERFUCKER. It goes with fish, meat, and any damn thing it wants to... ${ }^{23}$

What Williams didn't know at the time of his ad lib performance was that there did in fact exist a man named Donald Rege who was a wine maker and the proprietor of a store specializing in the sale and distribution of an assorted variety of "Rege" wines. Of course, Williams had not meant to disparage Donald Rege or his wine. How could he have? He had never heard of either of them. He was simply clowning around. But when Donald Rege found out about the routine, he brought suit against the comedian and his record company, claiming that Williams' monologue had caused him and his wine company "embarrassment, humiliation ridicule and anxiety."

Donald Rege lost his defamation suit - but not because Robin Williams and Polygram had never heard of Rege wines. The fact that Williams had no knowledge of Rege wines and therefore could not have intended to injure its reputation was irrelevant to the question of whether his comedy routine was defamatory. The reason why the lawsuit failed was because the court rejected Rege's claim that Williams' joke did harm to his reputation by associating his wines with African Americans. Believe it or not, Donald Rege actually tried to argue that his reputation was injured because his good name was associated with "a socio-economic group of persons commonly considered to be the anti-

\footnotetext{
Mayer Pictures Ltd. (1934), 50 T.L.R. 581 (C.A).

23 Polygram Records, Inc. v. Superior Court, 216 Cal. Rptr. 252 (Ct. App. 1985).
} 
thesis of wine connoisseurs." 24 This argument failed. Given the recipient-centered nature of defamation, the court held that the relevant question was whether Williams' association of Rege Wines with reggae music would lower the reputation of Donald Rege in the estimation of the community. The court ultimately found that the wine maker's claim to be "utterly untenable." 25

This example nicely illustrates one of the central aims of defamation law - namely, its attempt to define the realm of socially unreasonable communication. As one American legal scholar has described the law of defamation,

It pronounces the defendant's communication uncivil not because it caused direct and immediate harm to the plaintiff's psyche or property but because it diminishes her in the eyes of others. Doctrinal orthodoxy dictates that defamation does not provide compensation for emotional disturbance, but rather remedies a wrongful disruption in the "relational interest" that an individual has in maintaining personal esteem in the eyes of others. ${ }^{26}$

By recognizing certain communications as a wrongful interference with an individual's relational interests, it has been said that one of the primary functions of defamation law is to police violations of a society's "rules of civility." 27 Those who subscribe to this point of view see the law of defamation as premised on the recognition of a reflexivity in the relationship between individuals and their communities. Just as an individual's identity is constituted through an identification with particular communities (through an internalization of the rules and values of those communities), so too are the identities of those various communities dependant on the reciprocal observance of the rules

24 Ibid. at 261.

25 Ibid.

${ }^{26}$ Lidsky, supra note 16 at 14.

27 R.C. Post, "The Social Foundations of Defamation Law: Reputation and the Constitution," (1986) 74 Cal. L. Rev. 691 at 710-11. 
of civility that they have prescribed. By prohibiting socially unreasonable communications that cause reputational harm to individuals, defamation law is said to foster the preservation of a community's identity since it allows individuals within that community to interact and develop shared values and beliefs.

In order to enforce defamation law's rules of civility, a judge must rely on her or his own implicit vision of community life. ${ }^{28}$ One aspect of this is that alleged defamatory communications cannot be considered apart from the context in which they are made. ${ }^{29}$ As one court put it, "Words, like people, are judged by the company that they keep." 30 Of course, the circumstances in which the communication is made are also important to consider. For example, the same remark, when communicated to different audiences or when disseminated through different media might be defamatory in one instance though not in others. As Justice Clement once stated:

It is the circumstances in which a statement is made that gives it colour, meaning and thrust: they may combine to make a statement, seemingly innocuous in itself, an infamous defamation of a person who is caught and pointed to by those circumstances. $^{31}$

While this judicial pronouncement most certainly applies to statements made online, there is perhaps a more important point that needs to be made about the relevance of context and circumstances in the case of electronic communication. In the electronic environment, the context

${ }^{28}$ Lidsky, supra note 16 at 37.

${ }^{29}$ See e.g. O'Malley v. O'Callaghan (1992), 1 Alta. L.R. (3d) 88 (Q.B.); Crandall v. Atlantic School of Theology (1993), 120 N.S.R. (2d) 219 (S.C.).

30 Per Weltner J. in Anderson v. Southeastern Fidelity Insurance Co., 251 Ga. 556, 307 S.E. 2d 499 at 500 (1983).

${ }^{31}$ Per Clement J.A. in Fraser v. Sykes , [1971] 3 W.W.R. 161 at 166 (Alta. C.A.), aff'd (sub nom. Sykes v. Fraser) [1974] 1 S.C.R. 526. 
and circumstances underlying a communication will often spark a flame that adds emotional injury to insult. In other words, it could turn out that electronic communication, by its very nature, tends to produce a greater number of emotionally abusive and deeply hurtful statements. If this is true, one

might reasonably expect a proliferation of defamation lawsuits in correlation with the increasing use of the Internet as a communications medium.

This possibility notwithstanding, the flames of electronic misfire, though emotionally hurtful, will not always result in a tendency to lower the reputation of the targeted individual in the estimation of the community - especially when one takes into account the culture, context and circumstances of electronic interaction. Thus it is doubtful whether such misfires in communication will always call for the legal protections provided by defamation law, which aims to secure the protection of individuals' relational interests, while balancing those interests against other core values such as freedom of expression and freedom of the press. In order to gain a clearer understanding of the factors that need to be considered when determining whether a statement is made in the online setting should be understood in a defamatory sense, it is therefore necessary to investigate the nature of electronic communication.

\section{Communication in the Electronic Milieu}

There are a number of different ways to interact online. One of the most prevalent forms of online communication is Usenet. In essence, Usenet is a world-wide distributed discussion system. It consists of a set of newsgroups with names that are classified hierarchically by subject. Messages on any given subject are posted to a particular newsgroup by interested individuals. These messages are then broadcast to other computer systems via the Internet. The net effect is an asynchronous public discussion that hosts a wide variety of participants. Usually it is possible to post anonymous messages to Usenet, though this is not always the case with newsgroups that are moderated by an intermediary. Many newsgroups are unmoderated, leaving the norms of communication to be 
established by newsgroup participants. ${ }^{32}$ Usenet was the medium through which David Rindos was defamed.

A second form of online interaction is facilitated by LISTSERV, a system that makes it possible to create, manage and control electronic mailing lists on a host computer. ${ }^{33}$ The chief difference between Usenet and LISTSERV is that the former generates open, public communications while the latter is used to set up exclusive mailing lists. By setting up mailing lists, the LISTSERV host can create exclusive group and thereby temper the level of discussion. Both Usenet and LISTSERV can be distinguished from private email communications where one party chooses who he or she wishes to communicate with on any given occasion.

A third form of online interaction is realtime chat. Because this form of communication is conducted in real time, individuals are usually able to choose their interlocutors. Unlike Usenet and LISTSERV, the communications are not logged and therefore last only as long as the conversants remain in the chatroom. In this form of interaction the participants' identities are more significant, though they are not fixed. Depending on the particular Internet service, the participants are often allowed to choose various features of their online identities. ${ }^{34}$

There are other media of online communication. Some are more passive in nature than those discussed above. Perhaps the most popular form of online communication occurs through the development of a Web site which is made available for others to browse. Sometimes Web site hosts allows visitors to post messages. Other times they do not.

32 Sometimes known as Netiquette. See online: What is Usenet? <http://www.faqs.org/faqs/usenet/what-is/part1> (last modified: 29 December 1999).

${ }^{33}$ See online: What is Listserv?

$<$ http://members.aol.com/Shugosha/listserv.htm\#Whatis> (last modified: 17 February 1998).

${ }^{34}$ See L. Lessig, “The Path of Cyberlaw” (1995) 104 Yale L.J. 1743. 
The above forms of online interaction each embody in their own way to three important differences between communication in the electronic milieu and other contexts in which defamatory communications might take place. The first difference is that the technology-mediated and text-based character of electronic communication makes the process of communication more difficult, and the incidence of miscommunication more likely. The second difference is that the nature of social interaction in the online setting has a tendency to increase hostile communications that might be considered defamatory. The third difference is that the cultural context and standards of communication that develop in online communities will reduce the significance of these communications, potentially rendering harmless otherwise defamatory remarks by virtue of the culture in which they are pronounced. Let us consider each of these in turn.

\section{Difficulties in the Communication Process}

The received view is that face to face conversation is the de facto standard of human communication. As one author puts it, "face-to-face conversation is the basic and primary use of language, all others being best described in terms of their manner of deviation from that base." ${ }^{\text {35 }}$

As the 'basic' language setting, ${ }^{36}$ face to face conversation has the following qualities, which can be divided into three major groups:

Aspects of space and time:

- participants share a physical environment (copresence)

- participants see each other (visibility)

- participants hear each other (audibility)

- actions of each party are perceived without a perceptible delay (instantaneity)

${ }^{35}$ C. Fillmore, "Pragmatics and the Description of Discourse" in P. Cole, ed., Radical Pragmatics (New York: Academic Press, 1981) at 152.

${ }^{36}$ H. Clark, Using Language (Cambridge: University Press, 1996). 
Aspects of medium

- the medium of communication fades quickly (evanescense)

- there is no permanent record of the actions (recordlessness)

- participants can simultaneously produce and receive communication, and each of these activities can be carried out while the conversational partner is engaged in the same activities (simultaneity)

Aspects of control

- actions are formulated and carried out in real time (extemporaneity)

- participants determine for themselves the actions to be taken (self-determination)

- participants act as themselves, and not as conduits for the thoughts or ideas of others $(\text { self-expression })^{37}$

Face to face conversation is the only communication setting that has all of these qualities. All other language settings lack one or more of these characteristics.

Electronic communication is not a basic language setting. Interlocutors are usually physically separate. When the communication is text-based, participants can neither see nor hear one another, and the delay with which actions are perceived is variable (depending on Net traffic), but almost always evident. The electronic medium is neither evanescent nor recordless, and simultaneity, while possible, is certainly strained relative to the ease of simultaneous interaction in face to face conversation. It is only with regard to aspects of control (extemporaneity, self-determination, and selfexpression) that the context of electronic communication resembles that of face to face to face conversation. Even in these aspects, however, there are differences. Although participants largely determine their own actions, in some situations their communication choices are limited by software or by strong convention.

\footnotetext{
37 Ibid. at 9 .
} 
Communication in non-basic language settings often requires special techniques, training, and equipment in order to ensure that it is understood. It therefore stands to reason that communication in these contexts is also more difficult. When interlocutors are physically separate, the skill of writing or a technology like the telephone is required to support communication. If a medium of communication is not evanescent, communicators must take extra care to ensure that their intended meaning is evident in the permanent record, without benefit of the original context shared by the interlocutors. If control of the communication is held by someone other than the communicators, ${ }^{38}$ special skills are required for successful communication.

In electronic communication the requirement for technology and training to use the equipment is self-evident. What may be less obvious is that the computer-mediated text-only form of the communication also places additional demands on interlocutors, and additional stresses on the communication process. Communication involves the construction of shared meaning ${ }^{39}$ - and the non-basic language setting of electronic communication makes this process more challenging, more prone to misunderstanding, and potentially more prone to hostility.

Although the exchange of language is clearly central to human communication, most forms of communication also take advantage of, and indeed may rely on extra-linguistic cues. A wide variety of these cues are available in the basic language setting of face to face conversation. Qualities of voice, including tone, inflection, pacing, and pitch carry information about the speaker (such as gender, size and age). These qualities also carry information about the communicative intent. For example, utterances ending with an upward inflection are usually interpreted as questions. Gestures add to the information exchange, in some cases providing emphasis to the spoken words, and in other

38 As is the case, for example, in simultaneous translation, where the self-determined speech of one person completely controls what a second person says.

39 J.M. Atkinson \& J. Heritage, eds., Structures of Social Action: Studies in Conversation Analysis (Cambridge, UK: Cambridge University Press, 1984). 
cases augmenting spoken communication with critical information that is otherwise unavailable. For example, the use of pointing to indicate the referential targets of terms like 'this' or 'that'. Facial expressions carry additional information, serving both syntactic functions such as emphasizing words or marking questions and semantic functions such as showing personal reaction, or indicating thinking or remembering. ${ }^{40}$

In general, other language settings offer fewer extra-linguistic cues. Many of the cues utilized in face to face conversation rely on the fact that interlocutors share both space and time, implying copresence, visibility, audibility, and instantaneity. Once these conditions are violated, information from facial expressions, posture, gesture, and tone of voice is at best attenuated and possibly eliminated from the communication. The additional extra-linguistic cues that arise in mediated communication do not seem to be enough to fill the gap. For example, people are quite adept at making character assessments based on the cues of physical appearance and behaviour that are available in face to face communication. ${ }^{41}$ In written communication, however, these cues are unavailable, and the physical artifact _ the letter or memo itself _ carries the only information about the communicator and the communication. Although some have argued that handwriting analysis can offer character insights, research reveals that these attributions are largely inaccurate. ${ }^{42}$ Thus, when two parties talk face to face, one can 'read' the other's character and intentions, inferring much beyond the actual words that are spoken. In written communication, however, there is little information beyond that carried in the words themselves.

40 J.B. Bavelas \& N. Chovil, "Faces in Dialogue" in J. Russel \& J. M. Fernández-Dols, eds., The Psychology of Facial Expression (Paris: Cambridge University Press, 1997) 334.

41 W.B. Swann Jr., "Quest for Accuracy in Person Perception: A Matter of Pragmatics" (1984) 91 Psychol. R. 457.

42 R.P. Tett \& C.A. Palmer, "The Validity of Handwriting Elements in Relation to SelfReport Personality Trait Measures" (1997) 22:1 Pers. Indiv. 11. 
There is an extreme paucity of extra-linguistic information in an electronic interchange. Cues that rely on copresence, visibility, or audibility are clearly missing from text-based electronic communication. The physical artifact - the typed communication - is standardized to the point of offering virtually no additional insight into the communicator or the communication. One might argue that, in a realtime chat, the rate and pace of the interchange carries information. Thus, a message which appears more slowly on the computer screen could be perceived as being more thoughtful; a long pause in an interchange might indicate the holding back of information. The timing of the communication, however, is controlled as much by the medium itself as by the communicator (e.g., busy networks can result in long transmission times). In a realtime chat, there is no analogue of physical presence, which offers so much information in face to face conversation. In fact, in these electronic contexts, the only indication of the appearance of communication partners is their selfgenerated descriptions - and it is an accepted fact that these are largely fictitious. ${ }^{43}$ It seems, therefore, that even those extra-linguistic cues that are available in the online context are at best unreliable, and at worst completely uninformative.

Some users of electronic communication recognize the lack of extra-linguistic information in their communications. To address this deficit, they have built back into the exchange various extralinguistic cues. 'Emoticons' have developed as a way of explicitly coding emotional information in text in the form of stylized facial expressions. ${ }^{44}$ There are other cues available as well. For example, punctuation and capitalization (or the lack thereof) reflect the formality or informality of the communication. Conventions and standards have arisen which support the communication of

${ }^{43}$ See S. Turkle, Life on the Screen (New York, NY: Simon and Schuster, 1995) at 178.

${ }^{44}$ K. Rivera, N.J. Cooke \& J.A. Bauhs, "The Effects of Emotional Icons on Remote Communication" (CHI'96 Conference Proceedings on Human Factors in Computing Systems, Vancouver, B.C., 13-18 April 1996), online: CHI 96 Electronic Proceedings <http://www.acm.org/sigchi/chi96/proceedings/intpost/Rivera/rk_txt.htm> (date accessed: 14 June 2000). 
additional meaning or intent. Communicators use capitalization to denote shouting. Abbreviations such as IMHO (in my honest opinion) carry encoded linguistic information while at the same time indicating the status of the communicator within the group (since only those who are part of the group are likely to know appropriate abbreviations).

While these non-linguistic cues certainly help to clarify electronic communication, it remains true that they are not a natural adjunct. This is in direct contrast to the majority of extra-linguistic cues, such tone of voice, facial expression, gesture, or style of writing, that are present in other forms of communication. Spoken communication must have a tone of voice, just as the appearance of the script in handwritten letters is a required attribute, and facial expression is a necessary aspect of face to face conversation. Emoticons, capitalization, and punctuation in electronic communication must be, by contrast, constructed with specific communicative intent. Therefore, it cannot be assumed or even imagined that these extra-linguistic cues spontaneously reveal anything about the communicator or the communicative intent in an electronic communication.

This last point is particularly relevant because extra-linguistic cues typically serve at least two communicative functions. First, they are employed by the communicator to encode or emphasize aspects of the communication, as when a grin is used to signal an ironic or humorous statement. Second, they are interpreted by the receiver as providing insight, unintended on the part of the communicator, into both the message itself and the intentions and qualities of the person producing the message. Thus, receivers of a communication may 'read in' to posture, expression, tone of voice, or quality of writing interpretations that help to determine the (perhaps hidden) status, intent, and meaning of the communicator, as when non-verbal signals are interpreted as signs of interpersonal attraction. ${ }^{45}$ Without these cues, meaning and intention are less obvious, potentially leading to misunderstanding.

${ }^{45}$ K. Grammar, "Strangers Meet: Laughter and Nonverbal Signs of Interest in OppositeSex Encounters” (1990) 14:4 J. NonVerbal Behav. 209. 
Even in face to face conversation, communication regularly breaks down. "I didn't mean that!" is a familiar plaint in the midst of argument. If the construction of shared meaning is less than perfect in the optimal context of face to face conversation, it stands to reason that the unfamiliar setting of electronic communication, from which many extra-linguistic cues are eliminated, will only exacerbate the problem.

Most communication is subject to interpretation. "You jerk!" can be an insult, or it can communicate the level of trust and camaraderie between friends. The difference is not in the words that are spoken, but the more subtle cues of facial expression, tone of voice, and gesture. Research on aggression suggests that boys who are less adept at interpreting social cues are more likely to assume that ambiguous actions and communications are in fact hostile. ${ }^{46}$ This effect may be due to the effective absence of the information contained in the social cues, which would suggest that hostile attributions may be more common whenever social cues are attenuated. Electronic communication exactly fits this situation: interpretation of communications is more difficult precisely because the typical cues are absent. Research indicates that when emoticons are added to electronic messages, those same messages are less likely to be interpreted as 'flaming' ${ }^{47}$ Thus, adding some of the missing social cues to electronic messages reduces the likelihood that the messages will be interpreted as hostile.

Thus with respect to the communication process, it is clear that electronic communication increases the difficulty of the communication process. So far, we have suggested that this increased difficulty arises for two reasons: because special skills and equipment are required for electronic communication, increasing the demands on interlocutors, and because the absence of many social

\footnotetext{
${ }^{46}$ K.A. Dodge \& D.R. Somberg, "Hostile Attribution Biases Among Aggressive Boys Are Exacerbated Under Conditions of Threats To the Self” (1987) 58 Child Dev. 213.

${ }^{47}$ P.A. Thompsen \& D.A. Foulger, "Effects of Pictographs and Quoting on Flaming Electronic Mail" (1996) 12:2 Computers in Human Behavior 225.
} 
cues removes information from the communication. One likely consequence of this increased difficulty is an increase in miscommunication, and, potentially, an increase in hostile interchanges. 


\section{Hostile Social Interchange}

In face to face conversation, our communication partners are known to us. Unless we live with a perceptual disability, we both see and hear those with whom we communicate. In this basic language setting, it would be difficult to argue that undisguised communicators could remain unidentified. By contrast, in text-based electronic communication interlocutors are neither seen nor heard by each other. Furthermore, identities, in the form of user-selected login names, are created by a few simple keystrokes. We choose our on-line identities, connecting to and disconnecting from these assumed identities at will. Moreover, we attribute the same quality to our partners in electronic communication - that is, we assume there is a relatively transient connection between an on-line persona and a physical self.

In its most extreme form, this disconnection supports the anonymity of interlocutors who remain un-named, unrecognized by each other except as the joint participants in their interchange (thus, they would not recognize each other, for example, if they passed in the produce aisle of the local grocery, or if they met in a different electronic context where they carried different names), and lacking in the continuity of identity that would be required to connect past, present, and future communications as productions of the same individual. Typically, however, there is a less complete, but nonetheless significant, degree to which interlocutors remain unknown to each other in the electronic milieu. In many cases they are not identified by name or other information that links them to their real-world identities. In most cases, those engaged in electronically mediated text-based communication remain unseen and unheard by one another. As well, many people have multiple online identities that they use in different contexts, for varying lengths of time. Thus, even if on-line communicators do not remain completely anonymous, there is a heightened sense of anonymity or invisibility of self in the social interaction. ${ }^{48}$

${ }^{48}$ For a discussion of the various forms of anonymity, see C.R. Scott, "To Reveal Or Not To Reveal: A Theoretical Model of Anonymous Communication" (1998) 8:4 Comm. Theory 381. 
Social psychologists have studied the consequences of a sense of anonymity for human relationships and social interchange. Their research reveals that the disconnection of persona from person - of communication from communicator - has far-reaching implications. People regularly temper their actions and communications to be seen in the best possible light - a concern that becomes less relevant when they believe themselves to be anonymous. Thus, we are more likely to provide assistance, ${ }^{49}$ and less likely to act aggressively, ${ }^{50}$ when we can be identified.

According to many researchers, loss of identity results in unrestrained behaviour. ${ }^{51}$ Most likely, this is the result of the weakening of self-control mechanisms. Research suggests that these effects occur most often when the actor cannot be singled out or identified - a condition often present in the electronic context. Other research has challenged these results on the consequences of perceived anonymity, suggesting that instead of leading to aggressive behaviour, perceived anonymity leads to behaviour that is more consistent with group norms rather than societal norms or internal standards. ${ }^{52}$ These researchers suggest that under conditions of perceived anonymity individuals show an increased tendency to adhere to group norms, even when those norms condone behaviour that is contrary to their internal standards and beliefs. Consequently, one might well expect that the communication norms for on-line communities are likely to condone increased levels of aggression. For on-line communities, therefore, the two hypotheses about the impact of anonymity

49 H. Solomon, “Anonymity and Helping” (1981) 113:1 J. Soc. Psych. 37.

50 P.A. Ellison et al., "Anonymity and Aggressive Driving Behavior: A Field Study" (1995) 10:1 Journal of Social Behavior and Personality 265; J. Rehm, M. Steinleitner \& M. Lilli, "Wearing Uniforms and Aggression: A Field Experiment" (1987) 17:3 Eur. J. Soc. P. 57.

51 R.L. Dipboye, “Alternative Approaches to Deindividuation” (1977) 84 Psych. Bull. 1057.

52 T. Postmes \& R. Spears, "Deindividuation and Antinormative Behavior: A MetaAnalysis” (1998) 123:3 Psych. Bull. 238. 
on behaviour lead to exactly the same prediction: increased levels of aggressive interpersonal communication.

According to available evidence, individuals involved in computer-mediated communication are more likely to act outside of community norms. For example, the safety and anonymity of a computer-based matchmaking system results in a greater proportion of women initiating relationships, and thus breaking free from traditional sex-role stereotypes. ${ }^{53}$ At the same time, computer mediation seems to reduce differences in group participation that are based on status, reducing the degree to which high-status group members dominate communication. ${ }^{54}$ Computermediated interactions also to increase self-disclosure of participants ${ }^{55}$, particularly with reference to behaviours that are often under-reported, such as alcohol consumption. ${ }^{56}$

One commonly-cited consequence of these reduced constraints is increased interpersonal verbal aggression, or flaming. ${ }^{57}$, When previously unacquainted groups of 2-4 people are asked to

${ }^{53}$ B.W. Scharlott \& W.G.Christ, "Overcoming Relationship-Initiation Barriers: The Impact of a Computer-Dating System on Sex Role, Shyness, and Appearance Inhibitions" (1995) 11:2 Computers in Human Behavior 191.

54 V.J. Dubrovsky, S. Kiesler \& B.S. Sethna, "The Equalization Phenomenon: Status Effects in Computer-Mediated and Face-to-Face Decision-Making Groups" (1991) 6:2 Human-Computer Interaction 119; S.P. Weisband, "Group Discussion and First Advocacy Effects in Computer-Mediated and Face-to-Face Decision Making Groups" (1992) 53 Organ. Behav. Hum. Decis. Process. 352.

55 S.D. Locke \& B.O. Gilbert, "Method of Psychological Assessment, Self-Disclosure, and Experiential Differences: A Study of Computer, Questionnaire, and Interview Assessment Formats" (1995) 10:1 Journal of Social Behavior \& Personality 255.

56 J.C. Duffy \& J.J. Waterton, "Under-Reporting of Alcohol Consumption in Sample Surveys: The Effect of Computer Interviewing in Fieldwork" (1984) 79:3 Brit. J. Addict. 303.

${ }^{57}$ L.M. Jessup, T. Connolly \& J. Galegher, "The Effects of Anonymity on Group Process in Automated Group Problem Solving” (1990) 14 MIS Quarterly 312; S. Kiesler et al., "Affects in Computer-Mediated Communication: An Experiment in Synchronous 
reach decisions, computer-mediated groups show greater degrees of advocacy, more equal participation, and higher levels of verbal aggression compared to groups meeting face to face. ${ }^{58}$ Many studies have demonstrated that electronic communication is characterized, in part, by aggressive verbal interchanges. ${ }^{59}$ Thus, observation suggests that verbal aggression is indeed common in electronically mediated interchanges.

Aggressive acts tend not to occur alone. In fact, escalating aggression, in which the aggression of one party in the interchange is inflamed by the aggressive acts of the other party, has been identified as a common form of interpersonal conflict by communication researchers. ${ }^{60}$ Thus, hostile acts are

Terminal to Terminal Discussion.”(1985)1 Human-Computer Interaction 77; N.B. McCormick \& J.W. McCormick, "Computer Friends and Foes: Content of Undergraduates Electronic Mail” (1992) 8 Computers in Human Behavior 379. Note, however, that this claim of increased aggression in electronically mediated communication is not unchallenged. See J.B. Walther, J.F. Anderson \& D.W. Park "Interpersonal Effects in Computer-Mediated Interaction. A Meta-Analysis of Social and Antisocial Communication" (1994) 21:4 Comm. Res. 460.

${ }^{58}$ S. Kiesler \& L. Sproull, "Group Decision Making and Communication Technology" (1992) 52:1 Organizational Behavior \& Human Decision Processes 96; J. Siegel et al., "Group Processes in Computer-Mediated Communication" (1986) 37:2 Organ. Behav. Hum. Decis. Process. 157.

${ }^{59}$ L. Adrianson \& E. Hjelmquist, "Users Experiences of Com - a Computer-Mediated Communication-System" (1998) 7 Behaviour and Information Technology 79; T.W. Benson, "Rhetoric, Civility, and Community: Political Debate on Computer Bulletin Boards" (1996) 44:3 Comm. Q. 359; S. Kielser et al., "Affect in Computer-Mediated Communication: An Experiment in Synchronous Terminal-to-Terminal discussion" (1985) 1 Human-Computer Interaction 77; M.W. Smolensky, M.A. Carmody \& C.G. Halcomb, "The Influence of Task Type, Group-Structure and Extroversion on Uninhibited Speech in Computer-Mediated Communication" (1990) 6 Computers in Human Behavior 261.

${ }^{60}$ L.A. Baxter et al., "Ways of Doing Conflict: A Folk Taxonomy of Conflict Events in Personal Relationships" in P.J. Kalbfleisch, ed., Interpersonal Communication: Evolving Interpersonal Relationships (Hillsdale, New Jersey: Lawrence Erlbaum Associates, 1993) 89; L.M. Harris, K.J. Gergen \& J.W. Lannamann. "Aggression Rituals" (1986) 53:3 Comm. M. 252. 
observed to invoke retaliatory hostility, and hostile communications are no exception to this rule. In the electronic milieu, this type of conflict manifests as the typical 'flame war', which involves a prolonged exchange of aggressive communications between two or more interlocutors.

Aggressive communications often include potentially defamatory content. As we have seen, the anonymity inherent in the context of electronic communication will tend to increase the incidence of aggressive communication, and thus also increase the likelihood of defamatory content. The fact that aggressive communications will tend to provoke aggressive responses will exacerbate this tendency, and the public forum within which these interchanges take place may turn private insults and other aggressive discourse into defamatory comments.

\section{The Reduced Significance of Hostile Communication in the Online Setting}

As stated previously, the defamatory sense depends not only on the content of a communication, but also on the recipients' interpretation of that content. The same communication could be perceived as an accolade or an insult, depending on the context. Among computer hackers, being called a 'breakin artist' would be a compliment of the highest order, while among law enforcement officers or politicians the same comment could be taken as insulting and even defamatory. If it is common practice within a community to trade derogatory and even insulting remarks, such comments will be interpreted differently than if those comments breach the established social norms.

Sociological and psychological research reveals that norms of communication, including norms regarding dispute, differ across social groups. Thus, different social systems (of which cultures, communities, organizations, groups, families, and even individuals across time are examples) ${ }^{61}$, develop their own social norms. For example, apology norms differ between the Japanese and

${ }^{61}$ See R.E. Anderson and I. Carter with G.R. Lowe, Human Behavior in the Social Environment: A Social Systems Approach, 5th ed. (New York: Aldine de Gruyter, 1999). 
American contexts, in that a preferred apology in the American context is spontaneous and original, while in the Japanese context, conforming to common linguistic practice is more highly valued. ${ }^{62}$ People whose cultural heritage is Chinese, in contrast to those of an American background, tend to value emotional restraint and politeness as basic to communication. ${ }^{63}$ Different sub-groups of US citizens hold different norms for aggressive behaviour, with some subcultures more accepting of interpersonal aggression. ${ }^{64}$ We generally adhere to conversational rules in our communications, but people will normalize violations of these rules in response to task demands. For example, these norms may be breached to achieve fast, efficient communication. ${ }^{65}$ Finally, the same individual may adopt different standards and practices of communication in different contexts. For example, Mayan women typically adhere to a norm of amicable and cooperative conversation. In the courtroom, however, the accepted style of communication allows these same women to publicly display anger and indignation. ${ }^{66}$ Obviously, standards and practices of communication are affected both by those with whom one is interacting, and by the situation in which the interaction takes place.

On-line communities, being accessible to individuals across the globe, are unlikely to comprise groups of participants who share common communication standards and practices. As discussed above, these standards and practices differ across cultures, communities, and

${ }^{62}$ N. Sugimoto, "Norms of Apology Depicted in U.S. American and Japanese Literature on Manners and Etiquette" (1998) 22:3 I. J. I. R. 251.

${ }^{63}$ O. Shenkar \& S. Ronen, "The Cultural Context of Negotiations: The Implications of Chinese Interpersonal Norms" (1987) 23:2 J. App. Behav. Sci. 263.

${ }^{64}$ D. Cohen et al., "Insult, Aggression, and the Southern Culture of Honor: An Experimental Ethnography" (1996) 70:5 J. Pers. Soc. Psychol. 945; R.E. Nisbett, "Violence and U.S. Regional Culture" (1993) 48 Amer. Psychol. 441.

${ }^{65}$ C.A. Braithwaite, "Blood Money: The Routine Violation of Conversational Rules" (1997) 10:1Communication Reports 63.

${ }^{66}$ P. Brown, "Gender, Politeness, and Confrontation in Tenejapa” (1990) 13:1D. P. 123. 
circumstances. Given that some on-line communities bring together individuals from across the globe, cultural differences will virtually ensure that they do not at the outset share communication standards and practices. On-line standards and practices of communication will be established over time within a specific community, perhaps even explicitly negotiated by participants. Given this circumstance, it is interesting to note that the negotiation of personal boundaries within heterogeneous groups is often associated with incidents of miscommunication; ${ }^{67}$ furthermore, failure to recognize cultural differences (which may not be immediately obvious in an on-line interaction) leads to negative interpersonal evaluations, ${ }^{68}$ which could in turn promote hostile relations. We might expect, therefore, that in on-line communities miscommunication will be exacerbated, and verbal aggression increased, during the process of establishing group norms.

Historically, the Internet has been dominated by men, with women consistently representing the minority of Internet users. ${ }^{69}$ Men consistently show a greater degree of verbal aggression than do women. ${ }^{70}$ An examination of on-line discussion groups reveals that postings by men tend to be more adversarial than postings by women, including "put-downs, strong, often contentious assertions... (and) sarcasm." 71 Furthermore, men place an increased value on "freedom from censorship,

${ }^{67}$ S. Petronio et al., "(Mis)Communicating Across Boundaries: Interpersonal and Intergroup Considerations" (1998) 25:6 Comm. Res. 571.

68 B.L. Speicher, "Interethnic Conflict: Attribution and Cultural Ignorance” (1995) 5:3 The Howard Journal of Communications 195.

69 See online: CyberAtlas <http://www.cyberatlas.com> (date accessed: 14 June 2000).

70 A.M. Nicotera \& A.S. Rancer, "The Influence of Sex on Self-Perceptions and Social Stereotyping of Aggressive Communication Predispositions" (1994) 58:4 Western Journal of Communication 283.

71 S. Herring, "Gender Differences in Computer-Mediated Communication: Bringing Familiar Baggage to the New Frontier" (American Library Association Annual Convention, Miami, 27 June 1994) at para. 4, online: <http://www.cpsr.org/cpsr/gender/herring.txt> (last modified: 6 September 1994). 
forthright and open expression, and ... debate as a means to advance the pursuit of knowledge" in contrast to women, who tend to value harmonious interpersonal interaction. ${ }^{72}$ Thus, the research suggests that verbal aggression will be more common in contexts dominated by men.

Is there any evidence that these aggressive communications will come to define a group norm? As indicated above, research has shown that group members tend to conform to group standards, particularly when the individual members perceive themselves as being anonymous. Thus, especially under conditions approaching anonymity, the perceived group standards tend to override personal values or beliefs. The electronic milieu, in which real world identity is often not revealed, exactly fits this situation. At least one recent study reports data consistent with this assertion, demonstrating that individual conduct in realtime chat rooms, specifically participation in flaming, is affected by the perceived norms of the group. In this study, participants report that they are less likely to "send 'flaming' or hostile messages" when they "believe that there is an unwritten code of conduct that people must follow in chat rooms". ${ }^{73}$ It seems, therefore, that the tendency to conform to group behaviour in the on-line context may lead to a standard of communication that allows a greater degree of verbal aggression.

Where verbal conflict is both commonplace and accepted, the meaning of the interchange tends to lie outside the specific words that are exchanged. For example, although aggression is generally unacceptable, in a context where aggressive communications are common, these same communications are unlikely to engender strong social sanctions. Just as we evaluate the conduct of others relative to our own actions, ${ }^{74}$ we evaluate the communications of others relative to our own

72 Ibid. at para. 5 .

73 A. Bellamy \& C. Hanewicz, "Social Psychological Dimensions of Electronic Communication" (1999) 4:1 Electronic Journal of Sociology, online: Electronic Journal of Sociology <http://www.sociology.org/content/vol004.001/bellamy.html> (last modified: 10 June 1999).

74 M.D. Alicke "Egocentric Standards of Conduct Evaluation" (1993) 14:2 Basic and 
communications. Someone who sends an aggressive communication is less likely to attach blame to another person who does the same. Likewise, in a context where verbal aggression is common, the veracity of the statements is not at issue. In such situations, it is the process of the interchange that matters. ${ }^{75}$ The likely consequence is that such messages will increase in both intensity and frequency, reducing even further any possibility of negative sanctions for the aggression. Thus, among Jewish-American adults, argument is an accepted form of sociability ${ }^{76}$, and among Italian children, artful and creative participation in disputes is a valued skill. ${ }^{77}$ 'Ritual insulting' is honed to a fine art among some groups of adolescent males, with an important role in establishing power and leadership within the group. ${ }^{78}$

The meaning of a communication is determined jointly by the speaker, the listener, and the context within which the communication is produced. A remark that is insulting in one context may be a compliment in another context. If the situation is one in which aggressive and denigrating comments are regularly traded, these statements are likely to be discounted. Various factors in the online context tend to promote a norm in which aggressive communications are tolerated and perhaps even encouraged. It will be critical to consider this community norm when examining statements that might be considered defamatory.

Applied Social Psychology 171.

75 W. Labov, Language in the Inner City: Studies in the Black English Vernacular (Philadelphia: University of Philadelphia Press, 1972).

76 D. Schiffrin, “Jewish Argument as Sociability” (1984) 13:3 L. Soc. 311.

77 W. A. Corsaro \& T.A. Rizzo, "Disputes in the Peer Culture of American and Italian Nursery-School Children” in A.D. Grimshaw, ed., Conflict Talk: Sociolinguistic Investigations and Arguments in Conversations (Cambridge: Cambridge University Press, 1990) 21.

78 T. Kochman, "The Boundary Between Play and Nonplay in Black Verbal Dueling" (1983) 12 L. Soc. 329. 


\section{N The Defamatory Sense in Cyberspace}

As suggested above in Part III, the difficulties in the communication process, the hostile nature of online interchange and the reduced significance of hostile communication in the electronic milieu must be taken into account when determining whether a particular statement should be understood to convey a defamatory sense. Because cyberspace places interlocutors in a state of relative ignorance compared to those who enjoy the advantages of being able to interchange linguistic information face to face, it will be more difficult in some cases both for the conversants and for the courts to construct the meaning of particular statements. In the law of defamation, communications are generally construed by courts according to benchmarks such as "their common, natural, ordinary, plain, popular and usual sense". ${ }^{79}$ But what exactly do these supposed benchmarks mean in cyberspace? For example, if electronic interaction results in a significant increase in verbal aggression in certain

environments, as current research suggests, ${ }^{80}$ the "common, natural, ordinary, plain, popular and usual sense" of such communication will not necessarily be received and understood by its recipients in the same way that it would be received and understood in non-electronic media.

This will no doubt give rise to unexpected results in online defamation lawsuits. In some instances, online defamation suits will fail even though they might have succeeded had the same communication taken place in other contexts. Anomalies notwithstanding, if electronic communication is by nature more hostile, it will be important for judges and juries to take notice of this fact when determining whether a particular remark is defamatory. As discussed above, if meanspirited or aggressive statements would not be understood by the community of recipients as "socially

\footnotetext{
79 See Brown, supra note 14 at 172.

${ }^{80}$ Supra note 49.
} 
unreasonable communication", there is no principled reason for considering them defamatory regardless of whether those statement are clearly defamatory in other contexts.

Even if one leaves aside the heightened aggression often experienced in cybercommunications, other contextual considerations such as the lack of certain visual cues in the electronic milieu will also make it difficult to construe communications according to "their common, natural, ordinary, plain, popular and usual sense." As we have seen, the paucity of such cues tends to produce a wider range of ambiguity and misunderstanding. If interlocutors engaged in emotional debate regularly misunderstand one another, how are we to expect that a judge or jury is any better situated to determine what the effects of those heated exchanges will be in terms of the reputations of individuals targeted by such statements?

Perhaps the most serious challenge facing judges and juries charged with determining whether a particular communication is defamatory is the need to define community standards in the online setting. As an American author has pointed out, '[w]e may be living in the 'global village,' but the village is still full of separate communities..." ${ }^{\text {"1 }}$ How are courts to decide which is the relevant community standard to be applied? In reaching such a decision, judges and juries must be careful to recognize that new forms of communities are developing online. ${ }^{82}$ To reiterate an example from above, it is generally thought to be defamatory to accuse someone of committing a criminal act, e.g., the theft of property. ${ }^{83}$ But casting such aspersions within the technoculture of a computer hackers' discussion group on the Internet would not necessarily be understood in a defamatory sense. Within

${ }^{81}$ D. Loundy, "Whose Standards? Whose Community?" Chicago Daily Law Bulletin (1 August 1994) at 5.

${ }^{82}$ Howard Rheingold, The Virtual Community: Homesteading on the Electronic

Frontier, (Don Mills: Addison-Wesley Pub. Co., 1993); L. Lessig, supra note 33.

${ }^{83}$ Mack v. North Hill News Ltd. (1964), 46. W.W.R. 254 (Alta. S.C). 
the hacker community, such a remark would almost certainly be worn as a badge of honour, a badge that would in fact enhance, rather than diminish, a hacker's reputation. ${ }^{84}$

Of course, given that the appropriate inquiry of a court is to determine the tendency of such an accusation to result in reputational harm rather than to measure its real life effect, a community's actual reaction will not always be determinative. According to our courts, there are some segments of a society that are considered "so small as to be negligible." 85 Alternatively, there are other segments of society "whose standards are so anti-social that it is not proper for the courts to recognize them." 86 For example, it would be extremely unlikely that a member of the Ku Klux Klan would succeed in a defamation suit for being called a "nigger-lover". ${ }^{87}$ Though such a statement could well have the tendency to cause the Klansman to be shunned by his fellow Klansmen, our courts will not protect his relational interests on public policy grounds; courts will refuse to recognize his community's values in its construction of the sense of the words uttered. Canadian courts have characterized the judicial inquiry in terms of whether the statement is defamatory in the eyes of "right-thinking" members of the community. ${ }^{88}$ American law makers have phrased the inquiry in

${ }^{84}$ See e.g. D. Icove, K. Seger \& W. Von Storch, Computer Crime: A Crime Fighter's Handbook (Sebastopol, Cal.: O’Reilly \& Associates, 1995) at 61. See also I. Angus \& G. Blackwell, Phone Pirates (Ajax, ON: Telemanagement Press, 1993) at 14, and D. Fiery, Secrets of a Super Hacker (Port Townsend, Wash.: Loompanics Unlimited, 1994).

85 W. P. Keeton, ed., Prosser and Keeton on the Law of Tort, $5^{\text {th }}$ ed. (St. Paul, Minn.: West Pub. Co., 1984) at 777.

86 Per Deyo J. in Connelly v. McKay, 176 Misc. 685, 28 N.Y.S. 2d 327 at 329 (1941), citing Restatement of the Law of Torts $\$ 559$ (1938) at 142.

87 See Brown, supra note 14 at 191.

${ }^{88}$ See e.g. Tolley v. J.S. Fry and Sons, [1930] 1 K.B. 467 at 479, rev'd on other grounds [1931] A.C. 333. 
terms of what would be defamatory in the eyes of "a substantial and respectable minority." 89 In either case, as Holmes J. pointed out some years ago, "liability is not a majority vote." 90

Questions such as how far the boundaries of a community standard can be stretched (or how narrowly they can be constricted) are not unique to defamation in the online setting. The issue of community standards has always been a challenge for defamation law. ${ }^{91}$ A particular community standard will often depend upon "the temper of the times." 92 Electronic communication does, however, provide a new wrinkle. The Internet is said to have generated a number of new forms of communities.

People meet, and talk, and live, in cyberspace in ways not possible in real space. They build and define themselves in cyberspace in ways not possible in real space.

The typical form is something called a MUD or MOO, where people not only speak, but they act, or more precisely, emote; where they not only engage in conversation, but also move around, where they touch, they assault, they construct. Players build the world within which they live, and these constructions survive over time, for others to play with or change. This is a world where individuals not only are individually plastic, but where the world itself becomes plastic. ${ }^{93}$

Given the relative recency of online associations such as MUDs and MOOs, not to mention other theoretical uncertainties surrounding virtual communities, it is no easy task to predict or

${ }^{89}$ Restatement (Second) of Torts $\$ 559$ (1977).

90 Peck v. Tribune Co., 214 U.S. 185 at 190 (1909).

91 Likewise, it has also plagued other areas of law, e.g. obscenity law. See generally $R$. v. Butler, [1992] 1 S.C.R. 452; Miller v. California, 413 U.S. 15 (1973). For a discussion of the community standards problem associated with obscenity in the online setting see US v. Thomas, 74 F.3d 701 (6 ${ }^{\text {th }}$ Cir. 1996).

92 Per Fuld J. in Mencher v. Chesley, 297 N.Y. 94, 75 N.E. 2d 257 at 259 (1947).

93 See Lessig, supra note 33 at 1746-7. 
characterize who are the "right thinking members" of a particular online community or which groups will or should count as a "substantial and respectable online minority." A realization of this difficulty has spawned some scholars, such as Lessig, to offer the following prescription:

Cyberspace is elsewhere and before carving the First Amendment into its silicon, we should give the culture a chance to understand it. ... A prudent Court would let these issues evolve, long into this revolution, until the nature of the beast became a bit more defined. ${ }^{94}$

Although in an ideal world Lessig is most certainly right, the fact of the matter is that online defamation cases are clearly on the rise. ${ }^{95}$ More and more, our courts are being forced to confront the beast, despite the fact that the beast is not well understood. Some cases, like the case of the anthropology professor David Rindos, are relatively straightforward. Even if an online conference is less formal and more hostile than conferences such as those that academics attend in person, it is quite clear that the remarks made by the defendant Jarvis ${ }^{96}$ would indeed be understood as socially unreasonable communication by the members of the discussion group known as ANTHRO-L. It is equally obvious that the effect of those remarks would tend to injure the reputation of David Rindos, both online and offline, so as to entitle him to a substantial monetary award to compensate for the tortious interference with his relational interests. But other cases yet to be heard by our courts are sure to be more challenging.

\section{V.Conclusion}

94 Ibid. at 1753.

95 G. Matyjewicz, "When Chat Rooms Attack: An Approach to Cyberlibel” (1999) 5:6 The Internet Lawyer 7; J.R. Friedman, "Information Superhighway: Defamation" (1995) 64 Fordham L. Rev. 697 at 794.

96 Supra note 1. 
In this article, we have argued that some of the more difficult online defamation cases will require the courts to develop a deeper awareness of the contextual challenges that coincide with electronic communication. Other cases will require the courts to take into account the possibility that individuals tend to conduct themselves differently when they communicate electronically. Still other cases, we have also argued, will require the courts to consider the possibility that new and different kinds of communities exist online. Although these relatively unique aspects of the electronic milieu certainly do not delete or in any other way eliminate the legal norms applicable to other media of communication, the unique aspects of electronic communication might well have an impact on the court's inquiry as to whether right thinking members of the community would understand a particular communication as defamatory.

If this is correct, there is good reason to discard the naive point of view cited at the outset of this article, which holds that the medium of communication is irrelevant to an inquiry as to whether a particular communication is defamatory. There is also good reason to discard the conclusion said to flow from that point of view, namely, that a libel published through the Internet ought to be dealt with in exactly the same way that a libel published in a newspaper is dealt with.

It follows that there is a need for further empirical research about the content that is produced as a consequence of contextual challenges in electronic communication, as well as a need for further research on the nature of interaction between individuals and groups in the online setting. Equally important is the need for courts to pay attention to the results generated by such research. Unless they do, courts are sure to make mistakes when determining whether a particular electronic communication is defamatory. 